\title{
Effect of Current Density and Organic Additives on the Texture and Hardness of Ni Electrodeposited from Sulfamate and Watt's Solutions
}

\author{
Feng Yang ${ }^{1}$, Wenhuai Tian ${ }^{1}$, Hiroaki Nakano ${ }^{2}$, Hideaki Tsuji ${ }^{3}$, Satoshi Oue $^{2}$ and Hisaaki Fukushima ${ }^{2}$ \\ ${ }^{1}$ Department of Materials Physics and Chemistry, University of Science and Technology Beijing, Beijing, P. R. China \\ ${ }^{2}$ Department of Materials Science \& Engineering, Kyushu University, Fukuoka 819-0395, Japan \\ ${ }^{3}$ Department of Materials Process Engineering, Kyushu University, Fukuoka 819-0395, Japan
}

Ni electrodeposition was galvanostatically conducted over the current density range 500-2000 A/ $\mathrm{m}^{2}$ in unagitated sulfamate and Watt's solutions at 323 and $313 \mathrm{~K}$, respectively, to examine the effect of current density and organic additives on the texture, crystal orientation, and hardness of the deposited Ni. The overpotential for Ni deposition increased by the addition of polyethylene glycol (PEG) or saccharin in both sulfamate and Watt's solutions. The degree of increase in the overpotential in a PEG-containing solution was larger than that in a saccharincontaining solution. Ni deposited from an additive-free solution showed a morphology of field oriented texture type with the preferred orientation of the $\{100\}$ plane, while Ni obtained from a PEG- or saccharin-containing solution had the unoriented dispersed type without a preferred orientation in the region of some current densities. The region of the current density that resulted in the unoriented dispersed type in Watt's solution was larger than that in a sulfamate solution. The particle size of the deposited Ni decreased with the addition of PEG and saccharin. The hardness of the deposited Ni increased with PEG and saccharin, and was higher for the unoriented dispersed texture than for the field oriented texture. In additive-containing solutions, the hardness of Ni deposited from Watt's solution was higher than that from a sulfamate solution. [doi:10.2320/matertrans.M2009361]

(Received October 22, 2009; Accepted February 15, 2010; Published April 7, 2010)

Keywords: nickel electrodeposition, texture, crystal orientation, hardness, saccharin

\section{Introduction}

Electrodeposited Ni has been extensively used in dyes, molds, and screens for printing as electroforming films because of its excellent toughness, corrosion resistance, and wear properties. ${ }^{1-4)}$ Electroforming films are required to reduce the residual internal stress because of thick films. Therefore, a sulfamate solution has been mainly used to reduce the internal stress of the deposited Ni. However, the sulfamate ions are reported to decompose by anodic oxidation when an insoluble anode is used or a soluble anode is passivated. ${ }^{1,2,5-7)}$ Watt's solution has been widely used for plating, and can be applied to electroforming. ${ }^{8)}$

The mechanical properties of the deposited $\mathrm{Ni}$, such as strength, toughness, hardness, wear resistance, and ductility, depend on the structural factors such as texture, grain size, crystal orientation, lattice defects, impurities, and inclusions of $\mathrm{Ni}^{9}{ }^{9,10)}$ The structural factors of the deposited films are strongly affected by the electrolysis conditions. Therefore, the mechanical properties of the deposits are expected to depend on the electrolysis conditions. However, there have been very few studies on the effect of electrolysis conditions on the texture and crystal orientation of the deposited Ni.

In this study, the effect of the current density and organic additives on the texture and orientation of $\mathrm{Ni}$ deposited from sulfamate and Watt's solutions was discussed from the viewpoint of overpotential for Ni deposition. The effect of the current density and organic additives on the hardness of the deposited $\mathrm{Ni}$ was examined from the viewpoint of the $\mathrm{Ni}$ texture. Polyethylene glycol (PEG), which is known to have a straight chain structure, stable in an electrolytic solution, and saccharin to reduce the internal stress of deposited Ni were used as the organic additives.

\section{Experimental}

Table 1 shows the compositions of sulfamate and Watt's solutions and the electrolysis conditions for $\mathrm{Ni}$ deposition. The electrolytic solutions were prepared by dissolving reagent grade $\mathrm{Ni}\left(\mathrm{NH}_{2} \mathrm{SO}_{3}\right)_{2} \cdot 4 \mathrm{H}_{2} \mathrm{O}(1.24 \mathrm{~mol} / \mathrm{L})$, $\mathrm{NiCl}_{2} \cdot 6 \mathrm{H}_{2} \mathrm{O}(0.04 \mathrm{~mol} / \mathrm{L})$, and $\mathrm{H}_{3} \mathrm{BO}_{3}(0.49 \mathrm{~mol} / \mathrm{L})$ for the sulfamate solution, and $\mathrm{NiSO}_{4} \cdot 6 \mathrm{H}_{2} \mathrm{O}(0.91 \mathrm{~mol} / \mathrm{L})$, $\mathrm{NiCl}_{2} \cdot 6 \mathrm{H}_{2} \mathrm{O}(0.19 \mathrm{~mol} / \mathrm{L})$, and $\mathrm{H}_{3} \mathrm{BO}_{3}(0.49 \mathrm{~mol} / \mathrm{L})$ for Watt's solution in distilled and deionized water. The $\mathrm{pH}$ was adjusted to 4.0 (sulfamate solution) and 4.2 (Watt's solution) with sodium hydroxide. PEG $\left[\mathrm{HO}\left(\mathrm{C}_{2} \mathrm{H}_{4} \mathrm{O}\right)_{n} \mathrm{H}\right]$ of a mean molecular weight of $3 \times 10^{3}$ or saccharin was added in amounts of 0.1 or $3 \mathrm{~g} / \mathrm{L}$, respectively, to the electrolyte as an organic additive. Ni electrodeposition was performed in unagitated solutions under galvanostatic conditions of 1 to $1500 \mathrm{~A} / \mathrm{m}^{2}$ at $323 \mathrm{~K}$ (sulfamate solution) and $313 \mathrm{~K}$ (Watt's solution). Copper sheets measuring $1 \times 2 \mathrm{~cm}^{2}$ and $\mathrm{Ni}$ sheets $4 \times 4 \mathrm{~cm}^{2}$ were used as the cathode and anode, respectively. The cathode potentials were measured using a saturated $\mathrm{KCl}$, $\mathrm{Ag} / \mathrm{AgCl}$ reference electrode $[0.199 \mathrm{~V}$ vs. the normal hydrogen electrode (NHE), $25^{\circ} \mathrm{C}$ ]. The potentials were plotted with reference to the NHE. The deposits were dissolved from the cathode with nitric acid. Ni was quantitatively analyzed by inductively coupled plasma spectroscopy, and the cathode current efficiency for $\mathrm{Ni}$ deposition and partial current density of $\mathrm{Ni}$ were calculated.

The surface morphology of the deposited Ni was observed by SEM. The crystal orientation of the deposited Ni was determined using a method introduced by Wilson and Rogers $^{11)}$ with an X-ray diffraction intensity of 111 to 311 reflections. The particle size of the deposited $\mathrm{Ni}$ was calculated by Scherrer's equation ${ }^{12)}$ using the half width of the X-ray diffraction pattern of maximum reflection intensity. The cross-sectional texture of the deposited Ni was inves- 
Table 1 Solution compositions and electrolysis conditions.

\begin{tabular}{|c|c|c|c|c|}
\hline \multirow{6}{*}{$\begin{array}{l}\text { Sulfamate } \\
\text { soln. }\end{array}$} & $\mathrm{Ni}\left(\mathrm{NH}_{2} \mathrm{SO}_{3}\right)_{2} \cdot 4 \mathrm{H}_{2} \mathrm{O}\left(\mathrm{mol} \cdot \mathrm{dm}^{-3}\right)$ & 1.24 & & \\
\hline & $\mathrm{NiCl}_{2} \cdot 6 \mathrm{H}_{2} \mathrm{O}\left(\mathrm{mol} \cdot \mathrm{dm}^{-3}\right)$ & 0.04 & Current density $\left(\mathrm{A} \cdot \mathrm{m}^{-2}\right)$ & $0.5 \sim 5000$ \\
\hline & $\mathrm{H}_{3} \mathrm{BO}_{3}\left(\mathrm{~mol} \cdot \mathrm{dm}^{-3}\right)$ & 0.49 & Temperature $(\mathrm{K})$ & 323 (Sulfamate) \\
\hline & Polyethylene glycol $\left(\mathrm{g} \cdot \mathrm{dm}^{-3}\right)$ & 0.1 & & 313 (Watt's solution) \\
\hline & Saccharin $\left(\mathrm{g} \cdot \mathrm{dm}^{-3}\right)$ & 3.0 & Thickness of deposits $(\mu \mathrm{m})$ & 50 (Sulfamate) \\
\hline & $\mathrm{pH}$ & 4.0 & & 10 (Watt's solution) \\
\hline \multirow{5}{*}{$\begin{array}{l}\text { Watt's } \\
\text { soln. }\end{array}$} & $\mathrm{NiSO}_{4} \cdot 6 \mathrm{H}_{2} \mathrm{O}\left(\mathrm{mol} \cdot \mathrm{dm}^{-3}\right)$ & 0.91 & Cathode & $\mathrm{Cu}\left(1 \times 2 \mathrm{~cm}^{2}\right)$ \\
\hline & $\mathrm{H}_{3} \mathrm{BO}_{3}\left(\mathrm{~mol} \cdot \mathrm{dm}^{-3}\right)$ & 0.49 & Quiescent bath & \\
\hline & Polyethylene glycol $\left(\mathrm{g} \cdot \mathrm{dm}^{-3}\right)$ & 0.1 & & \\
\hline & Saccharin $\left(\mathrm{g} \cdot \mathrm{dm}^{-3}\right)$ & 3.0 & & \\
\hline & $\mathrm{pH}$ & 4.2 & & \\
\hline
\end{tabular}

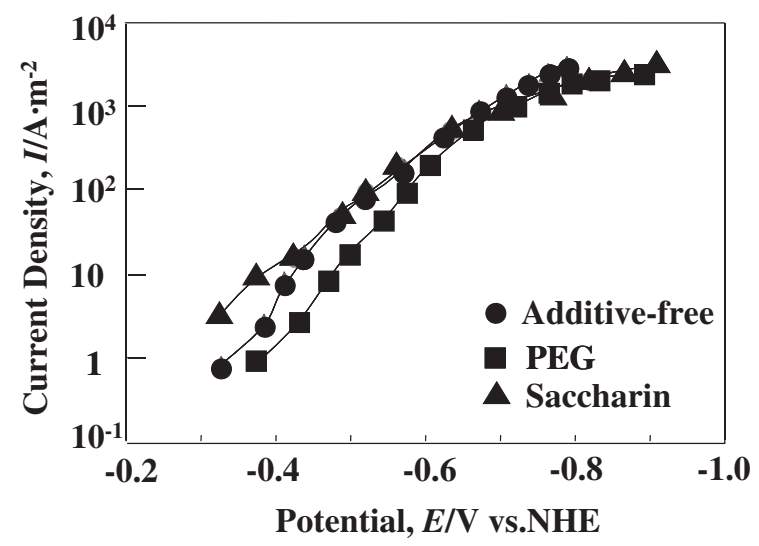

Fig. 1 Partial polarization curves for Ni deposition in sulfamate solutions.

tigated by electron back scattering pattern (EBSP). Prior to EBSP, $\mathrm{Cu}$ was electrodeposited on the deposited $\mathrm{Ni}$, and the cross section was polished by emery paper and buffed. It was then electropolished in a solution containing sulfuric acid (10 vol\%), methanol (10 vol\%), and ethanol ( $80 \mathrm{vol} \%)$, at $10 \mathrm{~V}$ for $1 \mathrm{~min}$. The Vickers hardness of the deposited Ni was measured in a cross section at a load of $0.2 \mathrm{~kg}$ for $15 \mathrm{~s}$.

\section{Results and Discussion}

\subsection{Texture of Ni deposited from the sulfamate solution}

Figure 1 shows the partial polarization curves for $\mathrm{Ni}$ deposition in a sulfamate solution. In a PEG-containing solution, Ni deposition was more polarized than in an additive-free solution at all current densities. Particularly at low current densities of $10-100 \mathrm{~A} / \mathrm{m}^{2}$, the polarization became large. In a saccharin-containing solution, the partial polarization curve of $\mathrm{Ni}$ was almost same as that with an additive-free solution at $10-500 \mathrm{~A} / \mathrm{m}^{2}$, but the Ni deposition was more polarized at current densities above $1000 \mathrm{~A} / \mathrm{m}^{2}$.

Figure 2 shows the surface SEM images of Ni deposited from the sulfamate solution. In an additive-free solution, the deposited $\mathrm{Ni}$ exhibited a smooth surface at low current densities of 100 and $500 \mathrm{~A} / \mathrm{m}^{2}$, while consisted of large size blocks at 1000 and $2000 \mathrm{~A} / \mathrm{m}^{2}$. In a PEG-containing solution, the deposited $\mathrm{Ni}$ consisted of blocks and granular crystals at all current densities. In a saccharin-containing solution, deposits showed a smooth surface above $500 \mathrm{~A} / \mathrm{m}^{2}$.
Figure 3 shows the crystal orientation of $\mathrm{Ni}$ obtained from a sulfamate solution. In an additive-free solution, the deposited Ni showed the preferred orientation of the $\{100\}$ plane, irrespective of the current density. The orientation index of the $\{100\}$ plane was almost constant, regardless of the current density. In a PEG-containing solution, the deposits consisted of unoriented crystals at $100 \mathrm{~A} / \mathrm{m}^{2}$, while the orientation index of the $\{110\}$ plane increased with the current density. In a saccharin-containing solution, the preferred orientation of $\mathrm{Ni}$ was $\{100\}$ at $100 \mathrm{~A} / \mathrm{m}^{2}$, but the deposited $\mathrm{Ni}$ became unoriented with increasing current density. Although PEG and saccharin affected the crystal orientation of the deposited $\mathrm{Ni}$, the current density dependence of the orientation in a PEG-containing solution was different from that in a saccharin-containing solution. Pangarov calculated the relative values of two-dimensional nucleation work on various crystal planes. ${ }^{13,14)}$ Assuming that the two-dimensional nuclei with the smallest nucleation work were formed at a given crystallization overpotential, he showed the overpotential dependence of the preferred orientation of various metals deposited from aqueous solutions. According to Pangarov, the preferred orientations of $\mathrm{Ni}$ with a face-centered cubic (FCC) structure are $\{111\},\{100\}$, and $\{110\}$ at low, middle, and high overpotentials for $\mathrm{Ni}$ deposition, respectively. That is, the preferred orientations of $\mathrm{Ni}$ are shifted from $\{111\}$ to $\{100\}$ and $\{110\}$ (in this order) as the overpotentials for Ni deposition increase. In this study, $\mathrm{Ni}$ deposited from the additive-free solution showed the preferred orientation of $\{100\}$, corresponding to the orientation at the middle overpotential for $\mathrm{Ni}$ deposition according to Pangarov. In the PEG-containing solution, the preferred orientation of the $\{110\}$ plane at a high current density above $1000 \mathrm{~A} / \mathrm{m}^{2}$ corresponds to that at a high overpotential for $\mathrm{Ni}$ deposition. As shown in Fig. 1, PEG increases the overpotential for $\mathrm{Ni}$ deposition above $1000 \mathrm{~A} / \mathrm{m}^{2}$. The crystal orientation at high current densities in a PEGcontaining solution can be explained in terms of Pangarov's calculations. However, the unoriented type of deposited $\mathrm{Ni}$ at high current densities in a saccharin-containing solution and at low current density in a PEG-containing solution cannot be explained by Pangarov's calculations. Pangarov also suggested that the work of the two-dimensional nucleation on various crystal planes could change, regardless of the overpotential, when certain foreign additives were 


\section{Additive-free}
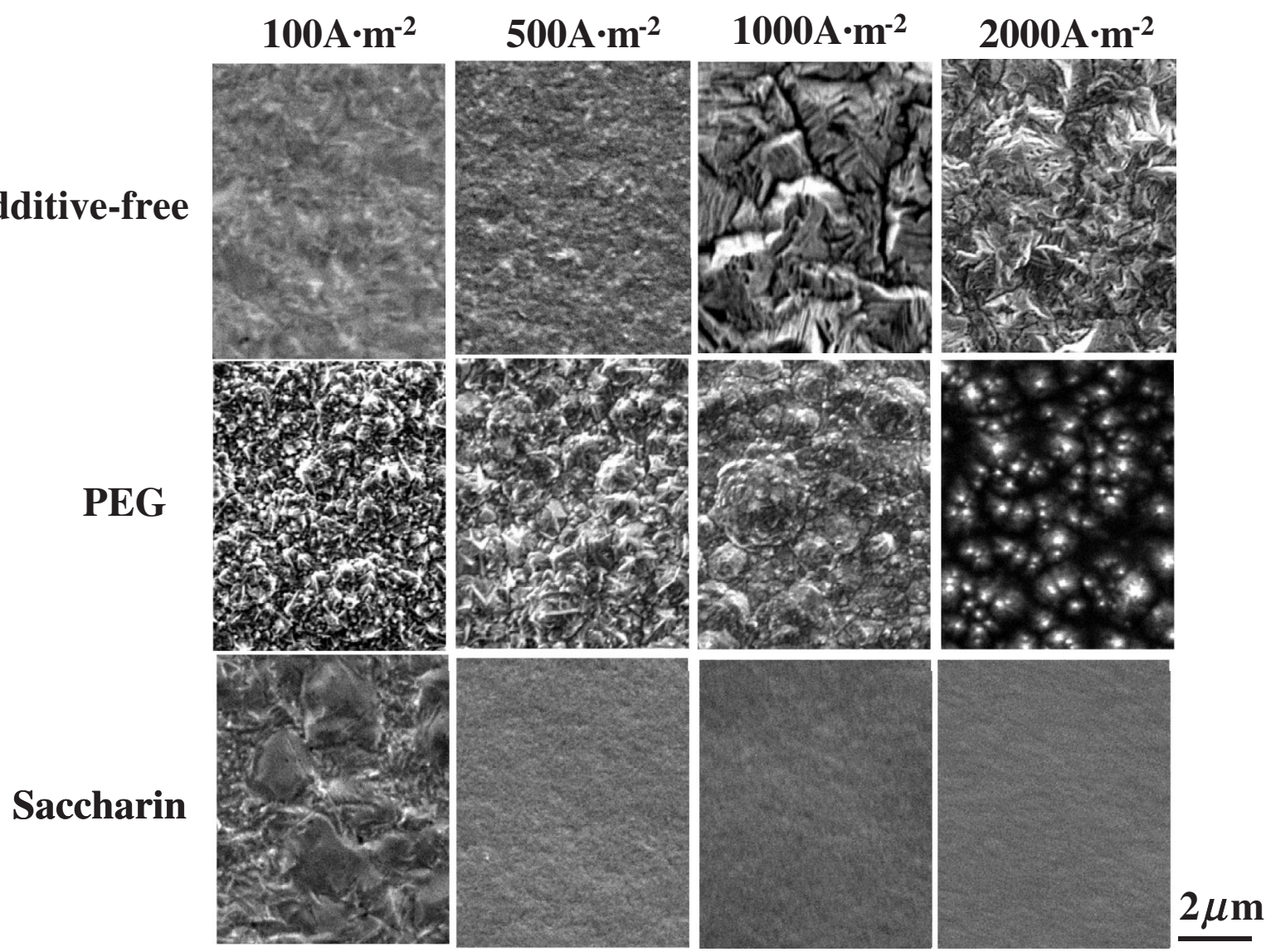

Fig. 2 Surface SEM images of Ni deposited from sulfamate solution. (Thickness of Ni: $50 \mu \mathrm{m}$ )

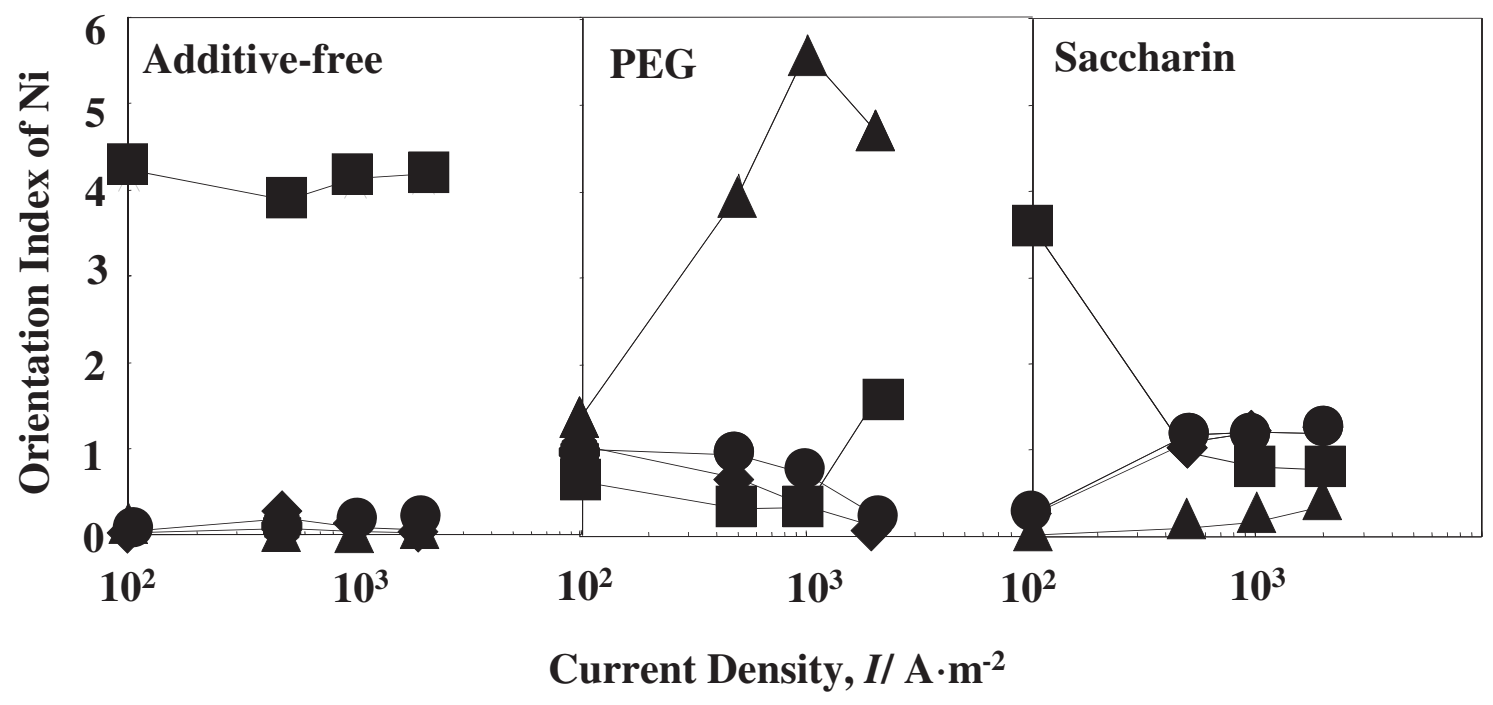

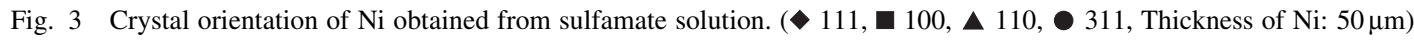

adsorbed on the cathode. ${ }^{13,14)}$ In this study, PEG and saccharin might affect the nucleation and growth of a specific crystal plane, and suppress the preferred orientation of the deposited $\mathrm{Ni}$.

Figure 4 shows the EBSP images of a cross section of $\mathrm{Ni}$ deposited from a sulfamate solution without organic additives. The deposited $\mathrm{Ni}$ initially showed small grains, but consisted of large columned crystals of a field oriented texture type at the middle stage. In the field oriented texture, a preferred orientation of specific plane occurs toward the electric field in deposition. ${ }^{15)}$ The columned crystals of $\mathrm{Ni}$ became large at a high current density of $1000 \mathrm{~A} / \mathrm{m}^{2}$. The side of the columned crystals showed the preferred orientations of the planes close to $\{100\}$ and $\{110\}$. The EBSP images of cross sections of Ni deposited from a sulfamate solution free from additives showed a field oriented texture, corresponding to the expectation from the crystal orientation of the surface, as shown in Fig. 3. 


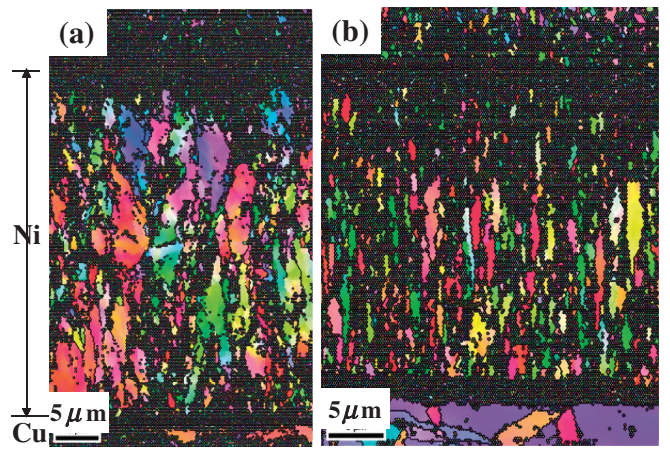

(a) $100 \mathrm{~A} \cdot \mathrm{m}^{-2}$ (b) $500 \mathrm{~A} \cdot \mathrm{m}^{-2}$ (c) $1000 \mathrm{~A} \cdot \mathrm{m}^{-2}$


Fig. 4 EBSP images of cross section of Ni deposited from sulfamate solution without organic additive.

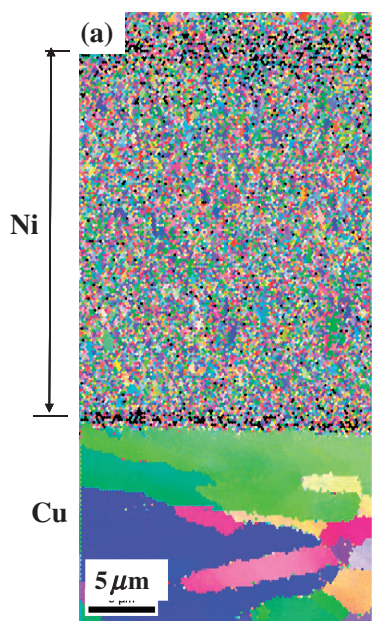

(a) $100 \mathrm{~A} \cdot \mathrm{m}^{-2} \quad$ (b) $500 \mathrm{~A} \cdot \mathrm{m}^{-2}$ (c) $1000 \mathrm{~A} \cdot \mathrm{m}^{-2}$

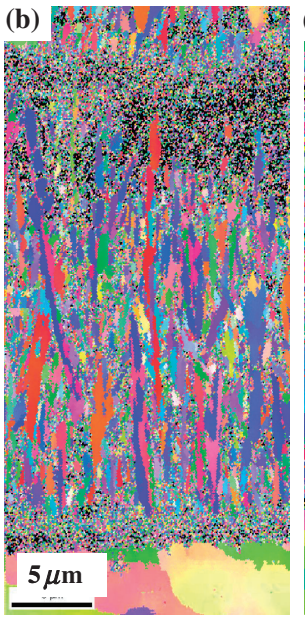

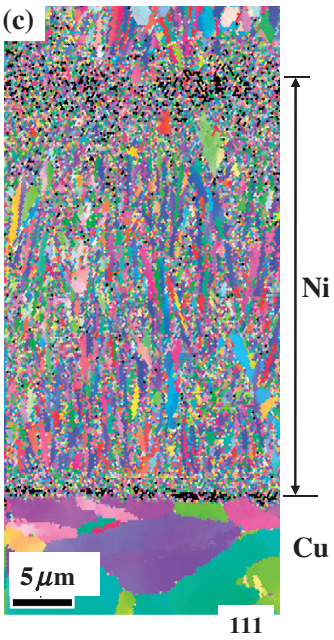

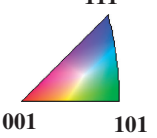

Fig. 5 EBSP images of cross section of Ni deposited from sulfamate solution containing PEG.

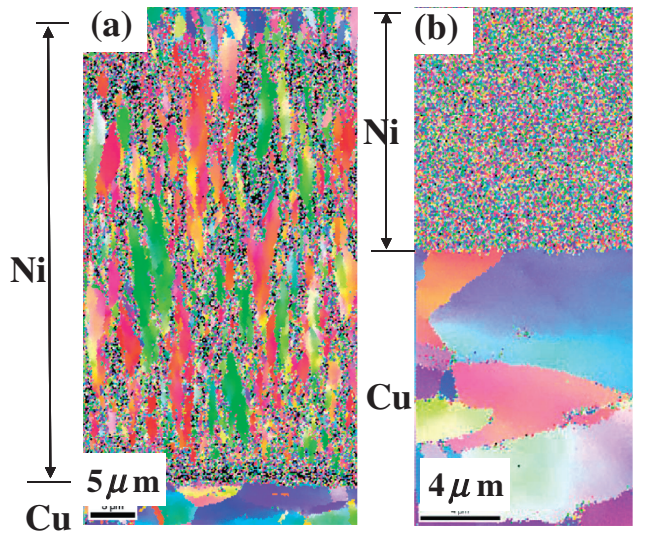

(a) $100 \mathrm{~A} \cdot \mathrm{m}^{-2}$

(b) $500 \mathrm{~A} \cdot \mathrm{m}^{-2}$ (c) $1000 \mathrm{~A} \cdot \mathrm{m}^{-2}$
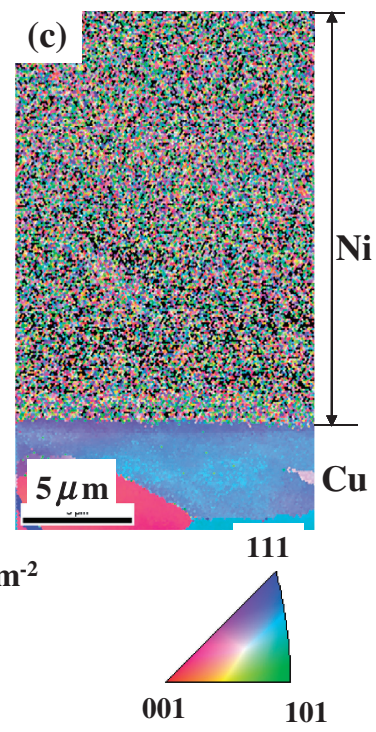

Fig. 6 EBSP images of cross section of Ni deposited from sulfamate solution containing saccharin. 


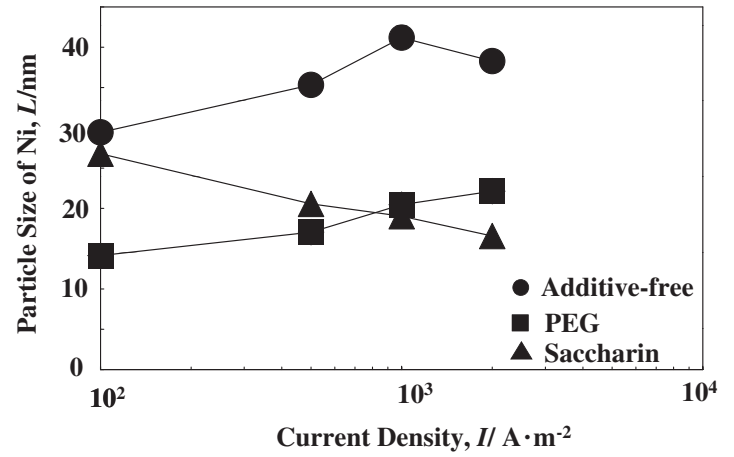

Fig. 7 Particle size of Ni obtained from sulfamate solution. (Thickness of Ni: $50 \mu \mathrm{m}$ )

Figure 5 shows the EBSP images of a cross section of $\mathrm{Ni}$ deposited from a PEG-containing solution. The deposited Ni showed the unoriented dispersed type of small grains at $100 \mathrm{~A} / \mathrm{m}^{2}$, while it showed a field oriented texture at 500 and $1000 \mathrm{~A} / \mathrm{m}^{2}$. In the unoriented dispersed type, the deposits consisted of small grains without the preferred orientation of a specific plane. ${ }^{15}$ ) The width of the columned crystals obtained at $1000 \mathrm{~A} / \mathrm{m}^{2}$ was smaller than that at $500 \mathrm{~A} / \mathrm{m}^{2}$, and the columned crystals deposited from a PEG-containing solution were smaller than that from a PEG-free solution, as shown in Fig. 4.

Figure 6 shows the EBSP images of a cross section of $\mathrm{Ni}$ deposited from a saccharin-containing solution. The deposited Ni showed a field oriented texture at $100 \mathrm{~A} / \mathrm{m}^{2}$, as it did with an additive-free solution. The sides of the columned crystals showed the preferred orientations of $\{100\}$ and $\{110\}$. The length of the columned crystals obtained from a saccharin-containing solution was shorter than those from additive-free and PEG-containing solutions. At 500 and $1000 \mathrm{~A} / \mathrm{m}^{2}$, the deposits became the unoriented dispersed type, similar to $100 \mathrm{~A} / \mathrm{m}^{2}$ in a PEG-containing solution.

Figure 7 shows the particle size of $\mathrm{Ni}$ obtained from a sulfamate solution. The particle size of the deposited $\mathrm{Ni}$ increased with the current density in additive-free and PEGcontaining solutions, while it decreased with increasing current density in a saccharin-containing solution. PEG and saccharin decreased the particle size of $\mathrm{Ni}$ at all current densities. This is attributed to a suppression of normal growth of the deposited $\mathrm{Ni}$ by additives adsorbed on the $\mathrm{Ni}$ growth sites. In a PEG- or saccharin-containing solution, the relationship between the particle size and the texture of the deposited Ni indicated that the particle size of the unoriented dispersed type was smaller than that of the field oriented texture type. The measured Ni particle size was about 20 $40 \mathrm{~nm}$, whereas the grain size of the deposited $\mathrm{Ni}$ was several $\mu \mathrm{m}$, as shown in Figs. 2 and 4. It is reported that the grains of the deposits consist of many particles with a size of several tens of $n m .{ }^{16-20)}$ In this study, the particle size determined using a half width of X-ray diffraction pattern appears to correspond to the size of each particle forming the deposited Ni grains. As shown in Fig. 2, Ni deposited from a saccharincontaining solution was smoother than that from a PEGcontaining solution. This cannot be explained by the overpotential for $\mathrm{Ni}$ deposition. It has been reported that the

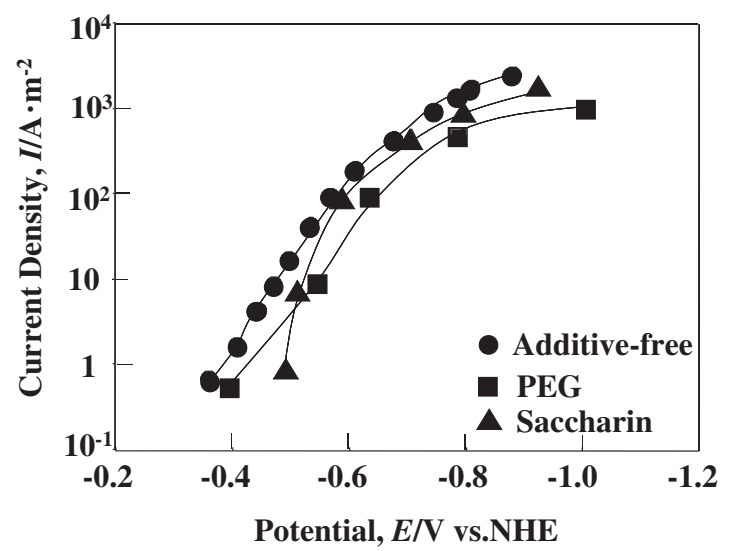

Fig. 8 Partial polarization curves for Ni deposition in Watt's solutions.

polymer additives such as PEG have a leveling effect that reduces asperity in a wavelength region larger than that of visible radiation (400 to $600 \mathrm{~nm}$ ), while the additives for gloss such as saccharin produce a leveling effect of atomic size. ${ }^{21)}$ This is caused by the suppression of $\mathrm{Ni}$ growth by saccharin adsorbed on the growth sites of $\mathrm{Ni}$.

\subsection{Texture of Ni deposited from Watt's solution}

Figure 8 shows the partial polarization curves for $\mathrm{Ni}$ deposition in Watt's solution. In a PEG-containing solution, $\mathrm{Ni}$ deposition was more polarized than with an additive-free solution at all current densities. In a saccharin-containing solution, the partial polarization curve of $\mathrm{Ni}$ was polarized, but the degree of polarization was smaller than that in a PEGcontaining solution. The trend of the effect of additives on the polarization curve of $\mathrm{Ni}$ in Watt's solution was almost identical to that in a sulfamate solution, but the degree of polarization effect of additives in Watt's solution was clearer than that in a sulfamate solution.

Figure 9 shows the surface SEM images of Ni deposited from Watt's solution. In an additive-free solution, the deposited Ni showed blocks of about $1 \mu \mathrm{m}$ at all current densities. In a PEG-containing solution, the deposited $\mathrm{Ni}$ consisted of platelets perpendicular to the substrate, which looked linear from the surface. In a saccharin-containing solution, deposits showed a smooth surface, irrespective of the current density, as in a sulfamate solution.

Figure 10 shows the crystal orientation of $\mathrm{Ni}$ obtained from Watt's solution. In an additive-free solution, the deposited Ni showed the preferred orientation of the $\{100\}$ plane at 500 and $1000 \mathrm{~A} / \mathrm{m}^{2}$, but the orientation index of the $\{110\}$ plane increased with the current density. According to Pangarov's calculations, as the overpotential for Ni deposition increases, the preferred orientation of the deposited $\mathrm{Ni}$ shifts from $\{100\}$ to $\{110\}$. The crystal orientation of $\mathrm{Ni}$ in an additive-free solution can be explained by Pangarov's calculations. In a PEG-containing solution, the deposits consisted of the unoriented crystals at 100 and $500 \mathrm{~A} / \mathrm{m}^{2}$, while the orientation index of the $\{110\}$ plane increased with the current density above $1000 \mathrm{~A} / \mathrm{m}^{2}$. This increase in the orientation index of the $\{110\}$ plane is caused by the increase in overpotential for $\mathrm{Ni}$ deposition above $1000 \mathrm{~A} / \mathrm{m}^{2}$. In a saccharin-containing solution, the deposited $\mathrm{Ni}$ became the 


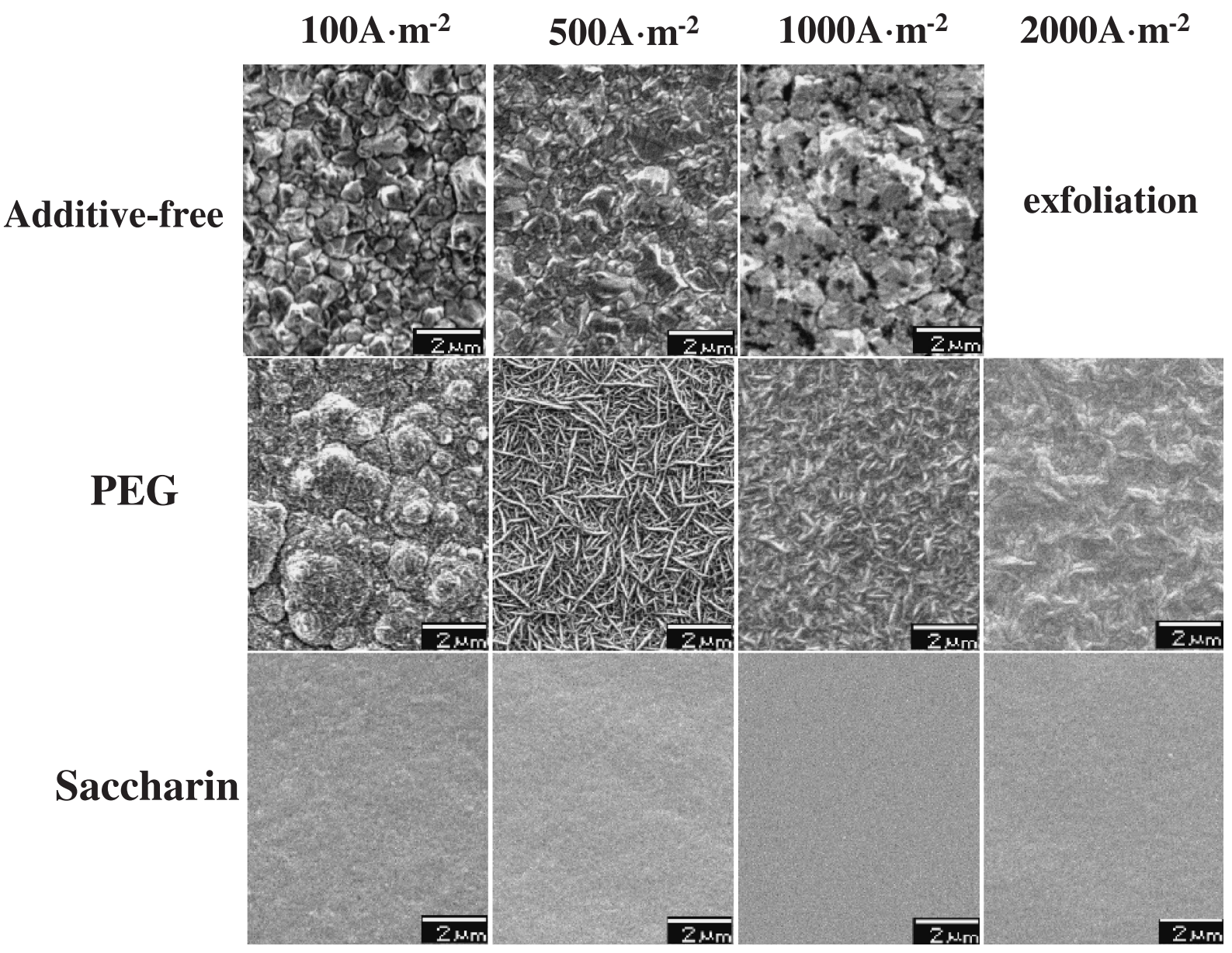

Fig. 9 Surface SEM images of Ni deposited from Watt's solution. (Thickness of Ni: $10 \mu \mathrm{m}$ )

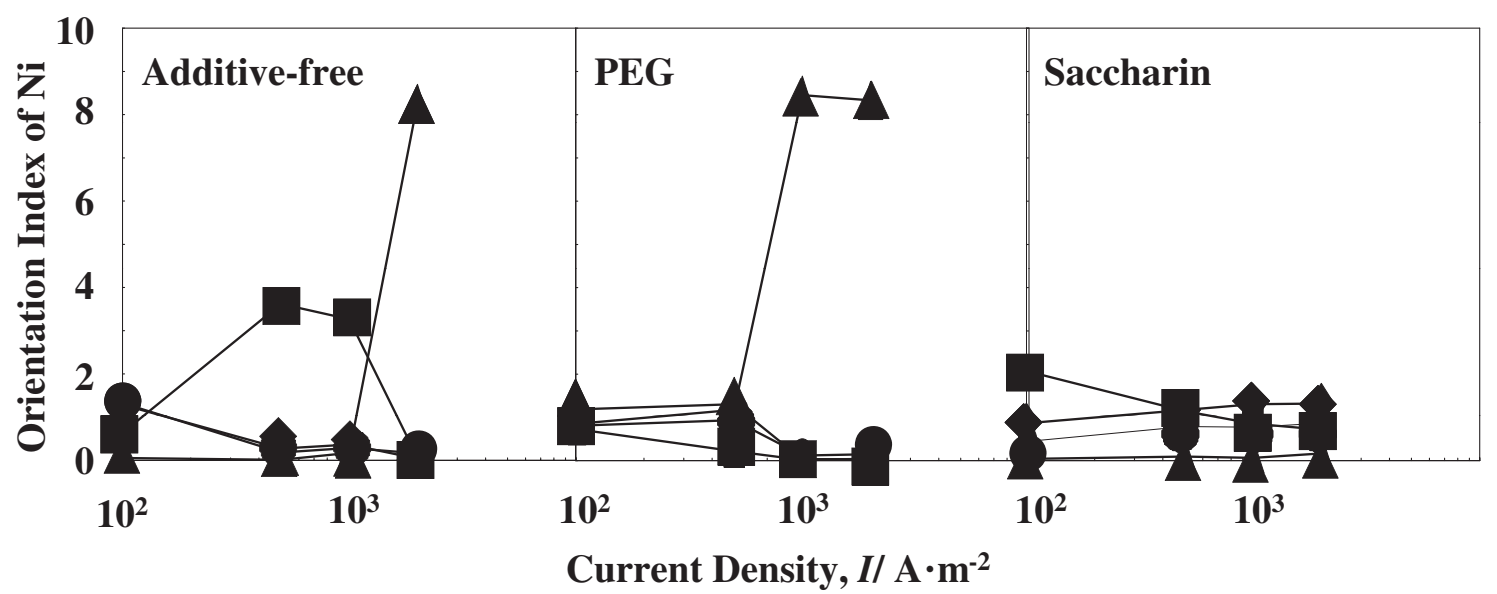

Fig. 10 Crystal orientation of Ni obtained from Watt's solution. ( 111, $\square$ 100, $\boldsymbol{\Delta} 110, \bullet 311$, Thickness of Ni: $10 \mu \mathrm{m})$

unoriented type at all current densities. As mentioned above, the effect of the current density and organic additives on the crystal orientation of Ni deposited from Watt's solution was almost identical with that from a sulfamate solution.

Figure 11 shows the EBSP images of a cross section of $\mathrm{Ni}$ deposited from Watt's solution without additives. The deposited Ni initially had small grains, but in the middle stage, consisted of large columned crystals of the field oriented texture type. The columned crystals of $\mathrm{Ni}$ became large at a low current density of $100 \mathrm{~A} / \mathrm{m}^{2}$.
Figure 12 shows the EBSP images of a cross section of Ni deposited from a PEG-containing solution. The deposited Ni showed the unoriented dispersed type of small grains at 100 and $500 \mathrm{~A} / \mathrm{m}^{2}$, while it showed the field oriented texture with the orientation of various planes at $1000 \mathrm{~A} / \mathrm{m}^{2}$.

Figure 13 shows the EBSP images of a cross section of $\mathrm{Ni}$ deposited from a saccharin-containing solution. The deposited $\mathrm{Ni}$ showed the unoriented dispersed type at all current densities. In Watt's solution, PEG and saccharin deposited $\mathrm{Ni}$ of the unoriented dispersed type. As seen from the compar- 


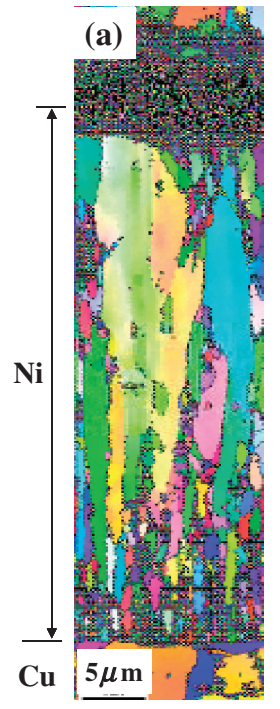

(a) $100 \mathrm{~A} \cdot \mathrm{m}^{-2}$

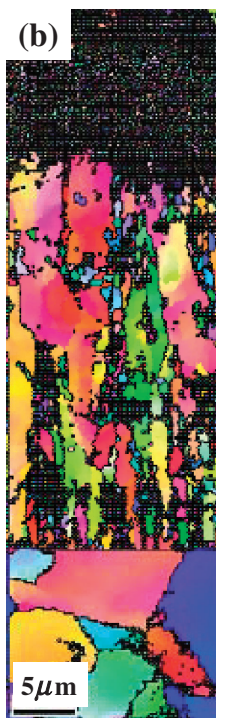

(b) $500 \mathrm{~A} \cdot \mathrm{m}^{-2}$ (c) $1000 \mathrm{~A} \cdot \mathrm{m}^{-2}$
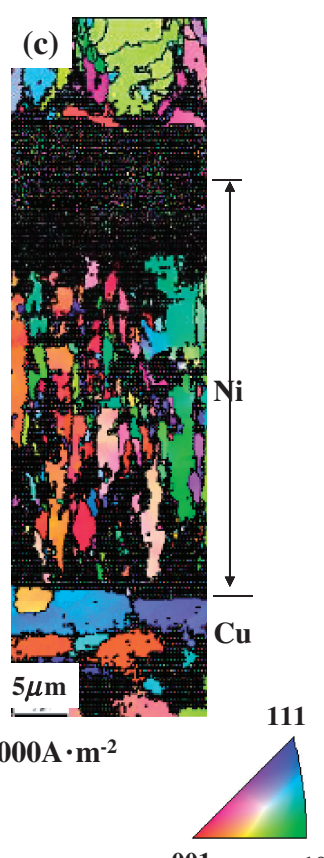

001
Fig. 11 EBSP images of cross section of Ni deposited from Watt's solution without organic additive.
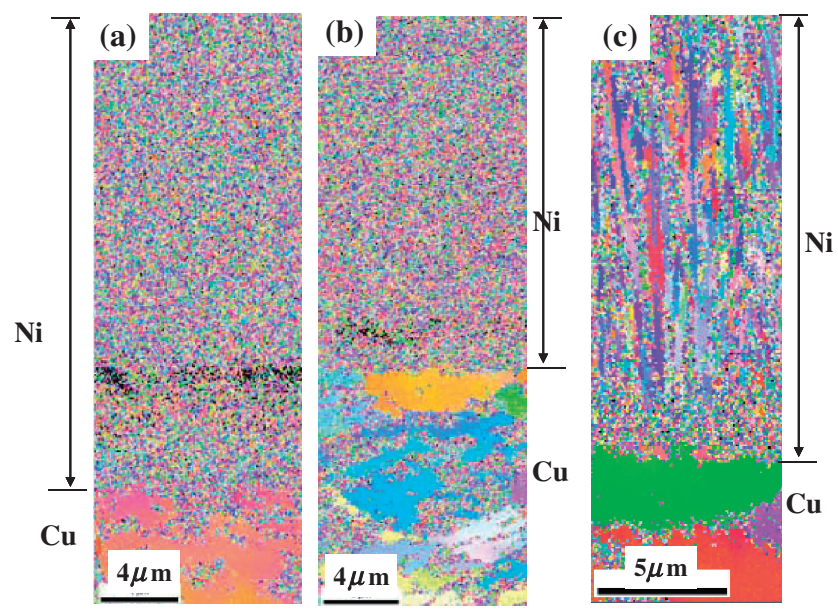

$\begin{array}{lll}\text { (a) } 100 \mathrm{~A} \cdot \mathrm{m}^{-2} & \text { (b) } 500 \mathrm{~A} \cdot \mathrm{m}^{-2} & \text { (c) } 1000 \mathrm{~A} \cdot \mathrm{m}^{-2}\end{array}$

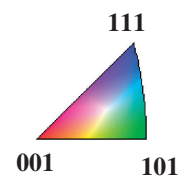

Fig. 12 EBSP images of cross section of Ni deposited from Watt's solution containing PEG.

isons between Figs. 5, 6, 12, and 13, the region of the current density that obtained unoriented dispersed type deposits from Watt's solution was larger than that for a sulfamate solution.

Figure 14 shows the particle size of $\mathrm{Ni}$ obtained from Watt's solution. In an additive-free solution, the particle size of the deposited Ni decreased with increasing current density because the nucleation rate of the deposits prevails over the growth rate as the overpotential increases. In a PEG- or saccharin-containing solution, the particle size of $\mathrm{Ni}$ was almost constant, regardless of the current density, and was smaller than that in an additive-free solution at all current densities.
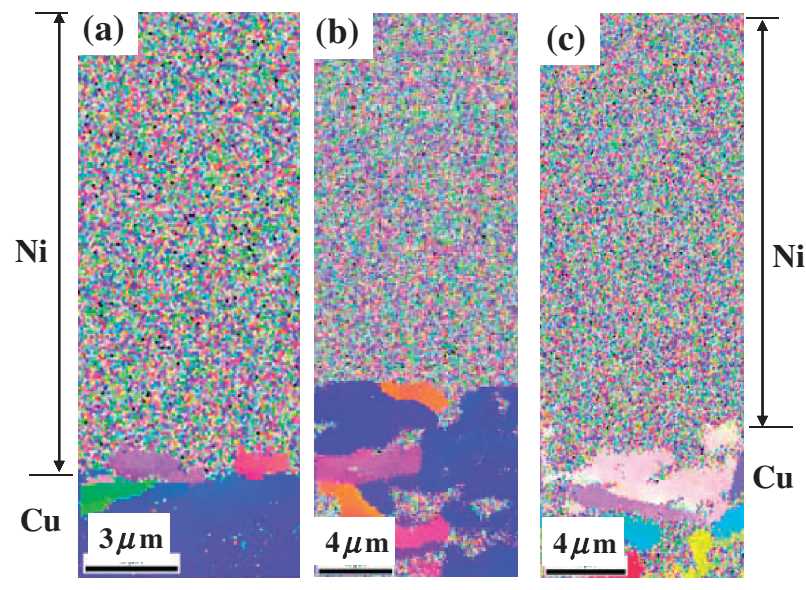

$\begin{array}{lll}\text { (a) } 100 \mathrm{~A} \cdot \mathrm{m}^{-2} & \text { (b) } 500 \mathrm{~A} \cdot \mathrm{m}^{-2} & \text { (c) } 1000 \mathrm{~A} \cdot \mathrm{m}^{-2}\end{array}$

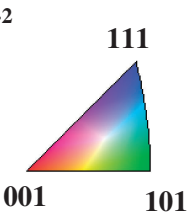

Fig. 13 EBSP images of cross section of Ni deposited from Watt's solution containing saccharin.

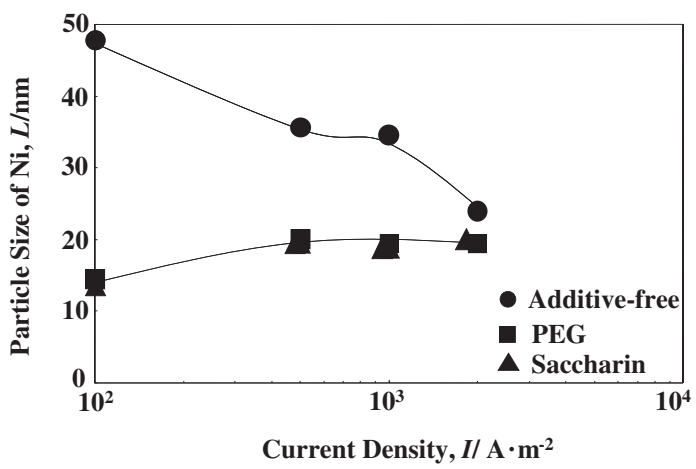

Fig. 14 Particle size of Ni obtained from Watt's solution. (Thickness of Ni: $10 \mu \mathrm{m})$

\subsection{Plating factors affecting the hardness of deposited Ni}

Figure 15 shows the Vickers hardness of Ni obtained from a sulfamate solution. The hardness of the deposited Ni was almost constant in the thickness direction, irrespective of whether PEG and saccharin were added or not. The Vickers hardness of Ni deposited from additive-free, PEG-containing, and saccharin-containing solutions were about 200, 350, and 500 , respectively. It has been reported that the organic additives such as PEG and saccharin codeposit with Ni and increase the hardness of deposited $\mathrm{Ni}^{8-10)}$ As shown in Fig. 7, the particle size of the deposited $\mathrm{Ni}$ was reduced by the use of additives. The increase in hardness from additives is attributed to the deposition of additives and the decrease in Ni particle size.

Figure 16 shows the effect of the current density and additives on the hardness of Ni deposited from a sulfamate solution. The current density had little effect on the hardness of Ni deposited from an additive-free solution; however, the hardness increased at a low current density of $100 \mathrm{~A} / \mathrm{m}^{2}$ in a PEG-containing solution, and decreased at $100 \mathrm{~A} / \mathrm{m}^{2}$ in a 


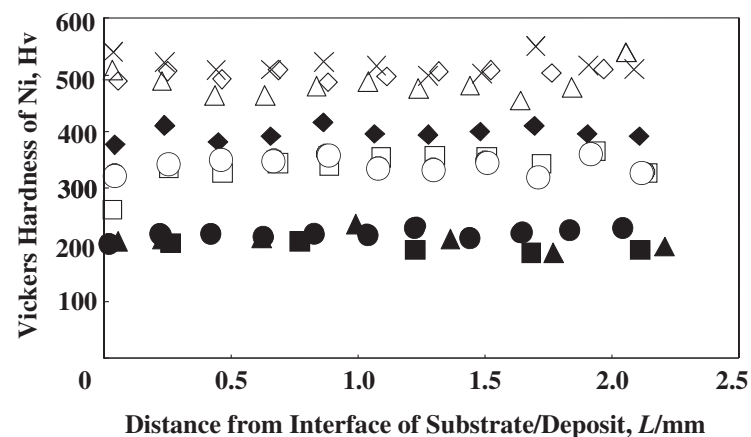

Fig. 15 Vickers hardness in thickness direction of $\mathrm{Ni}$ obtained from sulfamate solution. ( Additive-free $500 \mathrm{~A} \cdot \mathrm{m}^{-2}$, Additive-free $1000 \mathrm{~A} \cdot \mathrm{m}^{-2}, \Delta$ Additive-free $2000 \mathrm{~A} \cdot \mathrm{m}^{-2}, \diamond$ PEG $500 \mathrm{~A} \cdot \mathrm{m}^{-2}, \bigcirc \mathrm{PEG}$ $1000 \mathrm{~A} \cdot \mathrm{m}^{-2}, \square$ PEG $2000 \mathrm{~A} \cdot \mathrm{m}^{-2}, \triangle$ Saccharin $500 \mathrm{~A} \cdot \mathrm{m}^{-2}, \diamond$ Saccharin $1000 \mathrm{~A} \cdot \mathrm{m}^{-2}, \times$ Saccharin $2000 \mathrm{~A} \cdot \mathrm{m}^{-2}$ )

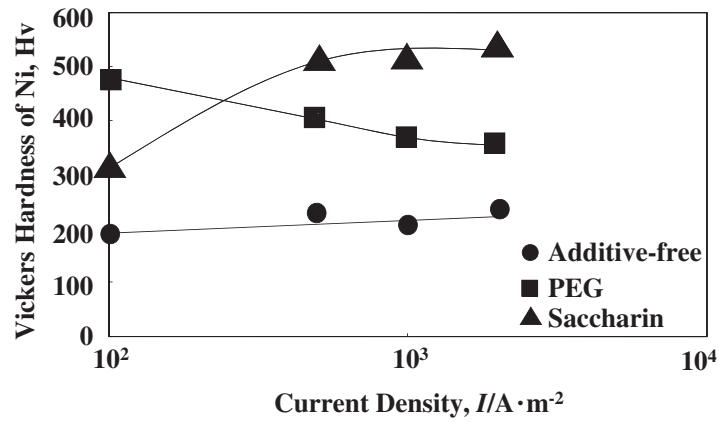

Fig. 16 Effect of current density and additive on the hardness of $\mathrm{Ni}$ deposited from sulfamate solution. (Thickness of Ni: $50 \mu \mathrm{m}$ )

saccharin-containing solution. In a PEG-containing solution, the deposited $\mathrm{Ni}$ showed the unoriented dispersed type at $100 \mathrm{~A} / \mathrm{m}^{2}$ and the field oriented texture above $500 \mathrm{~A} / \mathrm{m}^{2}$, as shown in Fig. 5. In a saccharin-containing solution, the deposits showed the field oriented texture at $100 \mathrm{~A} / \mathrm{m}^{2}$, and became the unoriented dispersed type above $500 \mathrm{~A} / \mathrm{m}^{2}$, as shown in Fig. 6. That is, in a solution with additives, the hardness of the deposited $\mathrm{Ni}$ of unoriented dispersed type was higher than that of the field oriented texture.

Figure 17 shows the Vickers hardness of Ni obtained from Watt's solution. The hardness of the deposited Ni increased significantly with the addition of PEG and saccharin, as with a sulfamate solution. The current density had little effect on the hardness of $\mathrm{Ni}$ in additive-free and saccharin-containing solutions, while the hardness increased at low current density of $500 \mathrm{~A} / \mathrm{m}^{2}$ in a PEG-containing solution. In a PEGcontaining solution, the deposited $\mathrm{Ni}$ showed the unoriented dispersed type at $500 \mathrm{~A} / \mathrm{m}^{2}$, but developed the field oriented texture with increasing current density, as shown in Fig. 12. That is, the hardness of the deposited $\mathrm{Ni}$ of unoriented dispersed type was higher than that of the field oriented texture, as with a sulfamate solution. In an additive-free solution, the preferred orientations were $\{100\}$ and $\{110\}$ at 1000 and $2000 \mathrm{~A} / \mathrm{m}^{2}$, respectively. However, there was little difference in the hardness between 1000 and $2000 \mathrm{~A} / \mathrm{m}^{2}$, showing no effect of preferred orientation plane on the hardness of the deposited Ni. As seen by comparing the Vickers hardness from sulfamate and Watt's solutions, in an

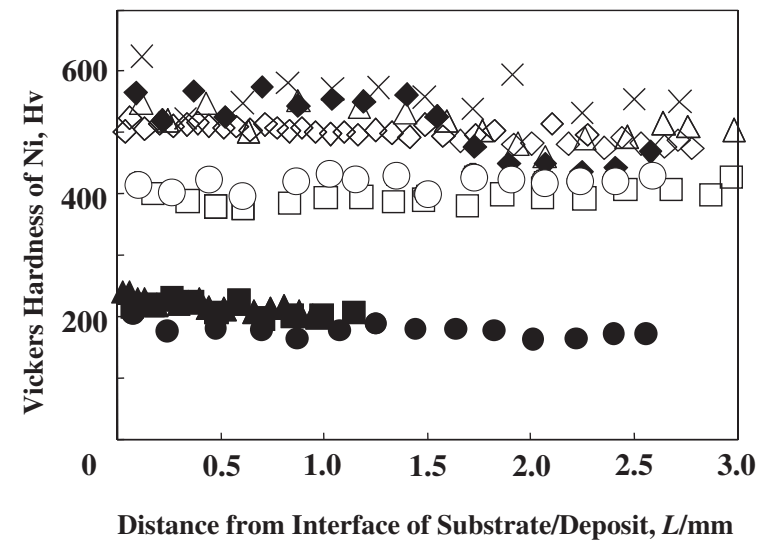

Fig. 17 Vickers hardness in thickness direction of Ni obtained from Watt's solution. ( Additive-free $500 \mathrm{~A} \cdot \mathrm{m}^{-2}, \boldsymbol{\text { Additive-free }} 1000 \mathrm{~A} \cdot \mathrm{m}^{-2}, \boldsymbol{\Delta}$ Additive-free $2000 \mathrm{~A} \cdot \mathrm{m}^{-2}, \diamond$ PEG $500 \mathrm{~A} \cdot \mathrm{m}^{-2}, \bigcirc$ PEG $1000 \mathrm{~A} \cdot \mathrm{m}^{-2}, \square$ PEG $2000 \mathrm{~A} \cdot \mathrm{m}^{-2}, \triangle$ Saccharin $500 \mathrm{~A} \cdot \mathrm{m}^{-2}, \diamond$ Saccharin $1000 \mathrm{~A} \cdot \mathrm{m}^{-2}, \times$ Saccharin $2000 \mathrm{~A} \cdot \mathrm{m}^{-2}$ )

additive-containing solution, the hardness of $\mathrm{Ni}$ deposited from Watt's solution was higher than that from a sulfamate solution. It has been reported that the residual internal stress of deposits from a sulfamate solution is smaller than that from Watt's solution. ${ }^{1)}$ This internal stress might affect the hardness of the deposited Ni.

\section{Conclusion}

The effect of current density and organic additives on the texture, crystal orientation and hardness of the Ni deposited from sulfamate and Watt's solution was investigated. In both sulfamate and Watt's solutions, the overpotential for $\mathrm{Ni}$ deposition increased by the addition of PEG or saccharin. The degree of increase in the overpotential in a PEGcontaining solution was larger than that in a saccharincontaining solution. $\mathrm{Ni}$ deposited from an additive-free solution showed a morphology of field oriented texture type with the preferred orientation of $\{100\}$ plane, while $\mathrm{Ni}$ obtained in solution containing a PEG or saccharin became the unoriented dispersed type without a preferred orientation in the region of some current densities. The region of the current density to obtain the unoriented dispersed type in Watt's solution was larger than that in sulfamate solution. The particle size of the deposited $\mathrm{Ni}$ decreased by the addition of PEG and saccharin. The hardness of the deposited $\mathrm{Ni}$ increased by PEG and saccharin, and the hardness of $\mathrm{Ni}$ with unoriented dispersed type texture was higher than that of the field oriented texture type. In additive-containing solution, the hardness of Ni deposited from Watt's solution was higher than that from sulfamate solution.

\section{REFERENCES}

1) H. Ise: Denchu Gizyutsu to Ouyo, (Maki shoten, Tokyo, 1996) p. 88.

2) D. A. Dibari: Nickel Electroforming, (INCO Ltd., New York, 1991) p. 26.

3) A. Kubota, M. Takada, T. Nakao, H. Nakano, S. Oue, T. Akiyama, H. Fukushima and R. Onodera: Tetsu to Hagane 86 (2000) 38-44.

4) N. Fujiwara, Y. Sugitani and T. Harada: Sumitomo Met. 30 (1978) 137-141. 
5) H. Nakano, S. Oue, S. Kobayashi, T. Akiyama, H. Kobayashi and T. Inoue: J. Sur. Finish. Soc. Jpn. 54 (2003) 533-538.

6) A. F. Greene: Plating 55 (1968) 594-600

7) L. Jiazhu, Z. Haiyan and Z. Liangyu: Plating and Surface Finishing, July (1990) 54-58.

8) M. Kawasaki and H. Enomoto: Mekki Kyohon, (Nikkan Kogyo Shinbunsya, Tokyo, 1988) pp. 79-89.

9) T. Hayashi: Kino mekki himaku no bussei, (Nikkan Kogyo Shinbunsya, Tokyo, 1986) pp. 6-11.

10) T. Hayashi: Kino mekki himaku no bussei, (Nikkan Kogyo Shinbunsya, Tokyo, 1986) pp. 71-81.

11) K. S. Willson and J. A. Rogers: Tech. Proc. Amer. Electroplaters Soc. 51 (1964) 92-95.

12) T. Watanabe: J. Sur. Finish. Soc. Jpn. 40 (1989) 280-286.
13) N. A. Pangarov: J. Electroanal. Chem. 9 (1965) 70-83.

14) N. A. Pangarov: Electrochim. Acta 7 (1962) 139-146.

15) R. Winand: J. App. Electrochemistry 21 (1991) 377-385.

16) K. Kondo, T. Murakami, F. Cerwinski and K. Shinohara: ISIJ Int. 37 (1997) 140-145.

17) H. Nakano, S. Oue, T. Miki, S. Kobayashi and H. Fukushima: ISIJ Int. 46 (2006) 106-110.

18) M. R. Zamanzad-Ghavidel, K. Raeissi and A. Saatchi: Mater. Lett. 63 (2009) 1807-1809.

19) M. Srivastava, V. E. Selvi, V. K. W. Grips and K. S. Rajam: Surf. Coat. Technol. 201 (2006) 3051-3060.

20) R. Mishra and R. Balasubramaniam: Corros. Sci. 46 (2004) 3019-3029.

21) H. Nawafune: Zisedai Mekki Gijyutsu, (Nikkan Kogyo Shinbunsya, Tokyo, 2004) pp. 10-11. 